\title{
Arahan Penataan Lingkungan Permukiman Kumuh Kecamatan Kenjeran dengan Pendekatan Eco-Settlements
}

\author{
Bayu Arifianto Muhammad dan Haryo Sulistyarso \\ Jurusan Perencanaan Wilayah dan Kota, Fakultas Teknik Sipil dan Perencanaan, \\ Institut Teknologi Sepuluh Nopember (ITS) \\ Jl. Arief Rahman Hakim, Surabaya 60111 Indonesia \\ e-mail: haryo.its@gmail.com
}

\begin{abstract}
Abstrak-Peningkatan jumlah penduduk dari periode ke periode diikuti juga padatnya permukiman penduduk. Hal ini berpotensi memunculkan permukiman kumuh yang berpengaruh negatif terhadap kualitas lingkungan.Dalam perencanaannya, Kota Surabaya mennggiatkan pekembangan dengan konsep berkelanjutan. Penelitian ini betujuan untuk menentukan arahan yang tepat dalam penataan lingkungan permukiman kumuh dengan pendekatan Eco-Settlements yang berkembang dari konsep pembangunan berkelanjutan. Sasaran yang disusun adalah mengidentifikasi karakteristik permukiman kumuh di Kecamatan Kenjeran dengan deskriptif kualitatif, Analisa faktorfaktor yang menyebabkan perkembangan permukiman kumuh menggunakan Delphi. Dan sasaran terakhir sekaligus output penelitian yang dihasilkan dari penelitian ini berupa arahan deskripitf dari setiap faktor-faktor yang mempengaruhi permukiman kumuh yang didasarkan pada kebijakan, base theory, dan penelitian yang telah dilakukan. Dari analisa tersebut didapat arahan secara garis besar berdasarkan faktor berpengaruh berupa penambahan dan peningkatan kualitas prasarana sanitasi, air bersih, drainase, dan rumah sehat, peningkatan daya dukung lingkungan dan sumber daya masyarakat, pemberdayaan ekonomi masyarakat, serta peningkatan kualitas institusi dan kesadaran akan kebijakan yang ada terkait pengelolaan permukiman kumuh.
\end{abstract}

Kata Kunci-Permukiman kumuh, Eco-settlements, penataan lingkungan

\section{PENDAHULUAN}

$\mathrm{P}$ ERMUKIMAN kumuh adalah permukiman yang tidak layak huni antara lain karena berada pada lahan yang tidak sesuai dengan peruntukkan atau tata ruang, kepadatan bangunan yang sangat tinggi dalam luasan yang sangat terbatas, rawan penyakit social dan penyakit lingkungan, kualitas umum bangunan rendah, tidak terlayani prasarana lingkungan yang memadai, membahayakan keberlangsungan kehidupan penghuninya [1]

Kota Surabaya sebagai kota metropolitan kedua di Indonesia juga mengalami fenomena permukiman padat penduduk. jumlah penduduk Kota Surabaya sampai dengan tahun 2014 adalah 3.200.424 dengan kepadatan penduduk rata-rata adalah 8.463 jiwa per $\mathrm{Km}^{2}$ [2] Kota Surabaya jika ditinjau berdasarkan lokasinya dapat dibedakan menjadi permukiman kumuh sekitar pantai dan tambak, di pinggiran sungai dan drainase kota, pinggiran rel kereta api, dan tengah kampung. Sedangkan berdasarkan tingkat kekumuhannya dapat dibedakan menjadi tiga tingkatan yaitu kumuh berat, sedang, dan ringan. Kecamatan Kenjeran merupakan salah satu kecamatan yang memiliki permukiman kumuh di Surabaya. Kecamatan Kenjeran memiliki luas wilayah kumuh sebesar 16,75 Ha Permukiman kumuh di Kecamatan Kenjeran. memiliki tipe permukiman kampung dan memiliki kualitas lingkungan permukiman yang rendah dengan karakteristik permukiman padat,bentuk permukiman tidak teratur (squatter), lebar jalan kecil,pengolahan limbah yang belum maksimal, prasarana air bersih yang lingkup pelayanannya belum merata, kondisi drainase yang sempit dan terhambat di beberapa titik, serta ruang terbuka hijau yang belum memadai [3]

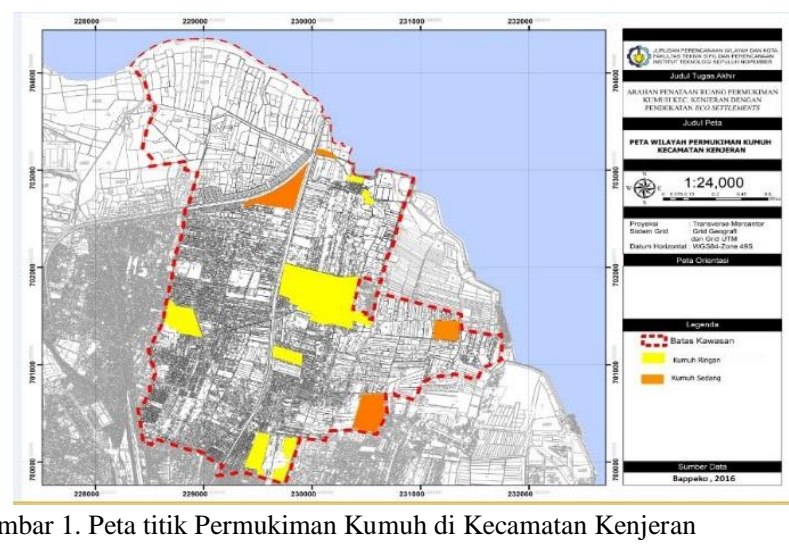

Berdasarkan pemaparan masalah diatas untuk mengurangi tingkat kekumuhan wilayah serta meningkatkan kualitas lingkungan pada Kecamatan Kenjeran dibutuhkan arahan penataan lingkungan permukiman kumuh Kecamatan Kenjeran. Eco settlements adalah suatu konsep penataan permukiman dengan mengharmoniskan aspek sosial, ekonomi, dan ekologi menuju keberlanjutan ekosistem dengan didukung oleh system kelembagaan yang kapabel [4] Pendekatan ini sejalan dengan prinsip pengembangan wilayah Kota Surabaya yang tercantum dalam RTRW dan RDTRK yaitu permbangunan yang berkelanjutan. 


\section{METODE PENELITIAN}

\section{A. Pendekatan dan Jenis Penelitian}

Pendekatan penelitian yang digunakan dalam penelitian ini adalah pendekatan positivisme [5] Jenis penelitian ini adalah penelitian deskriptif kualitatif

\section{B. Variabel Penelitian}

Variabel yang digunakan dalam penelitian ini antara lain : kualitas lingkungan dengan sub variabel air bersih, drainase, sanitasi, persampahan, aksesbilitas; rumah sehat dengan sub variabel kepadatan bangunan, bahan bangunan, pencahayaan, kualitas udara, sanitasi atau MCK, RTH privat; guna lahan sekitar dengan sub variabel penggunaan lahan sekitar dan ruang terbuka hijau; tingkat kesempatan kerja dengan sub variabel jenis pekerjaan; tingkat pendapatan dengan sub variabel jumlah pendapatan warga; tingkat pemberdayaan masyarakat dengan sub variabel swadaya masyarakat; tingkat kepadatan penduduk dengan sub variabel jumlah penduduk, dan jumlah penduduk pendatang (urbanisasi); Tingkat pendidikan; tingkat kesehatan; tingkat partisipasi dengan sub variabel partisipasi langsung dan tidak langsung; Budaya masyarakat, Kapasitas institusi dengan sub variabel dukungan kerjasama, dukungan kebijakan, dan dukungan pemerintah

\section{Mengidentifikasi karakteristik lingkungan Permukiman Kumuh Kecamatan Kenjeran}

Untuk mengetahui karakteristik lingkungan yang ada di wilayah permukiman kumuh Kecamatan Kenjeran. Dilakukan analisis kualitatif. terdapat 3 tahapan untuk mendapatkan data yang valid, yaitu reduksi data, penyajian data dan penarikan kesimpulan

D. Mengidentifikasi faktor-faktor yang mempengaruhi perkembangan permukiman kumuh di wilayah Kecamatan Kenjeran dengan indikator eco settlements

Dalam mengidentifikasi faktor-faktor yang mempengaruhi perkembangan permukiman kumuh di Kecamatan Kenjeran, penulis menggunakan alat analisa Delphi. Tahapan analisa Delphi yang dilakukan dalam penelitian meliputi :

1) Spesifikasi Permasalahan

Menentukan isu permasalahan yang akan dibahas dan dikomentari oleh para responden

2) Merumuskan Kuisioner

Menentukan poin-poin yang akan dimasukkan ke dalam kuisioner yang berupa daftar pertanyaan untuk dipakai pada putaran pertama dan selanjutnya

3) Wawancara Delphi Putaran I

Wawancara stakeholders untuk eksplorasi faktor-faktor yang mempengaruhi setelah mengetahui stakeholders kunci yang didapat dari analisa stakeholders

4) Analisis Hasil Wawancara

Analisis hasil wawancara berupa reduksi data yang merupakan proses memilih, memfokuskan, menyederhanakan, meringkas dan mentransformasikan data dari transkrip hasil wawancara

5) Iterasi dan Penarikan Kesimpulan
Iterasi dditujukan untuk memastikan (cross check) apakah faktor -faktor yang mempengaruhi berdasarkan hasil ringkasan wawancara sesuai dengan maksud yang diberikan oleh masing-masing stakeholders.

\section{E. Arahan Penataan Lingkungan Permukiman Kumuh} Kecamatan Kenjeran dengan Pendekatan Eco-Settlements

Dalam menentukan arahan penataan lingkungan permukiman kumuh di Kecamatan Kenjeran dengan pendekatan ecosettlements menggunakan Teknik analisis Triangulasi. Sumber dari analisis triangulasi dalam penelitian ini antara lain pengamatan fakta empiris peneliti, referensi dari studi literature, regulasi/kebijakan, dan studi pembanding di daerah lain. Analisis tersebut dengan mensitesakan keempat sumber sehingga didapatkan arahan penataan lingkungan permukiman kumuh Kecamatan Kenjeran.

\section{HASIL DAN DISKUSI}

\section{A. Indentifikasi Karaktristik Permukiman Kumuh Kecamatan Kenjeran}

Dalam analisis ini dua jenis permukiman kumuh yang terdapat pada Kecamatan Kenjeran diidentifikasi kedalam 4 karakteristik utama eco-settlements yaitu Ekologi (Lingkungan), ekonomi, Sosial dan Kelembagaan.

- Permukiman Kumuh Ringan

1) Ekologi

Kebutuhan air bersih, sanitasi warga sudah terpenuhi.Penanganan sampah sudah lebih dari $60 \%$ yang tertangani oleh TPA, Sedangkan drainase masih ditemukan drainase primer yang tergenang sampah,drainase sekunder dan tersier yang tersumbat sampah dan meluap. Aksesbilitas terdapat jalan yang belum memenuhi syarat luas jalan yaitu jalan lokal sekunder (5 meter) dan lingkungan $(<2$ meter) dan belum mengalami perkerasan atau pavingisasi. Luasan RTH public belum sesuai (19\%) dan kondisi rumah sehat yang sudah memenuhi syarat hanya aspek jenis bangunan dan ketersediaan MCK

2) Ekonomi

Jenis mata pencaharian penduduk pada permukiman kumuh ringan sebagai berikut

Tabel 1

Jenis Mata Pencaharian Penduduk

\begin{tabular}{|c|c|c|}
\hline $\begin{array}{c}\text { Kecamatan } / \text { Kel } \\
\text { urahan } \\
(3)\end{array}$ & $\begin{array}{l}\text { Kelompok } \\
\text { Masyarakat } \\
\text { (4) }\end{array}$ & $\begin{array}{l}\text { Kegiatan Ekonomi } \\
\text { (5) }\end{array}$ \\
\hline Tambak Wedi & $\begin{array}{l}\text { Kampung } \\
\text { Nelayan }\end{array}$ & 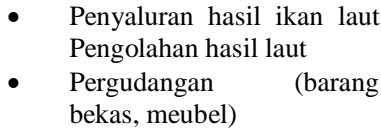 \\
\hline $\begin{array}{l}\text { Tanah Kali } \\
\text { Kedinding }\end{array}$ & Pedagang & $\begin{array}{ll}\text { - } & \text { Pedagang Pasar } \\
\text { - } & \text { Pengolahan hasil laut } \\
\text { - } & \text { Wirausaha }\end{array}$ \\
\hline $\begin{array}{l}\text { Sidotopo } \\
\text { Wetan }\end{array}$ & $\begin{array}{l}\text { Pekerja Industri } \\
\text { dan pedagang }\end{array}$ & $\begin{array}{ll}\text { - } & \text { Pedangan Pasar } \\
\text { - } & \text { Pekerja/pegawai } \\
\text { pabrik }\end{array}$ \\
\hline
\end{tabular}

Sumber. Survey Primer dan wawancara, 2015 


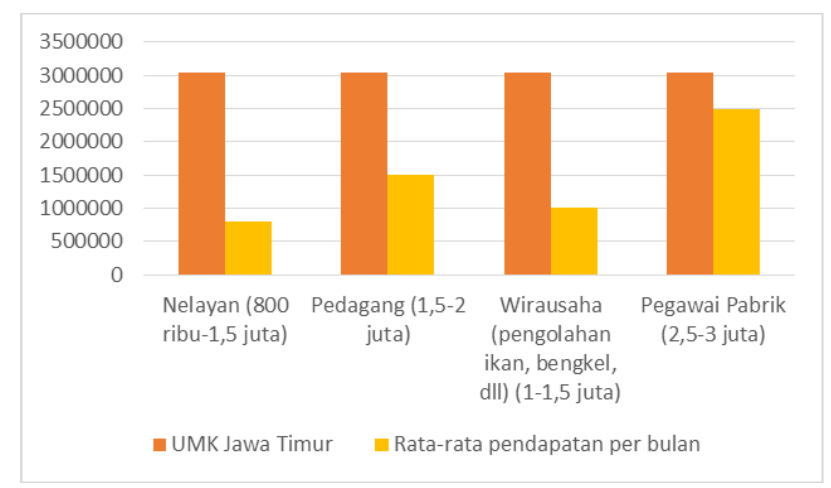

Gambar 2. Tingkat Pendapatan masyarakat dibanding UMK Kota Surabaya

3) Sosial

Tingkat partisipasi masyarakat pada Kecamatan Kenjeran > 60\% dari jumlah warga, dimana partisipasi masyarakat dibagi dalam partisipasi langsung berupa kerja bakti, bersih sungai, dan perbaikan jalan; dan partisipasi tidak langsung berupa perbaikan drainase, perbaikan jalan, bedah rumah, pelatihan kewirausahaan. warga di permukiman kumuh ringan sudah memiliki gaya hidup perkotaan, tetapi budaya pedesaan masih terlihat

4) Kelembagaan

Institusi yang langsung berhubungan dengan permasalah lingkungan permukiman kumuh di Kenjeran adalah Bappeko Kota Surabaya, Dinas PU dan Cipta Karya Kota Surabaya, Dinas Kebersihan dan Pertamanan Kota Surabaya, serta Instansi tingkat Kecamatan dan Kelurahan. Sedangkan Kebijakan yang bersangkutan langsung adalah RTRW Kota Surabaya, RDTRK UP Tambak Wedi, SPIPP, dan RP4D.

\section{- Permukiman Kumuh Sedang}

1) Ekologi

Kebutuhan air bersih hanya $80 \%$ yang terpenuhi sedangkan sisanya masih menggunakan sumur, sanitasi warga sudah terpenuhi $60 \%$ dimana lainnya masih membuang limbah langsung ke drainase atau pantai. .Penanganan sampah sekitar 50\% yang tertangani oleh TPA sedangkan lainnya masih memanfaatkan lahan kosong untuk membakar sampah, Sedangkan drainase masih ditemukan drainase primer yang tergenang sampah,drainase sekunder dan tersier yang tersumbat sampah dan meluap. Aksesbilitas terdapat jalan yang belum memenuhi syarat luas jalan lingkungan $(<2$ meter) dan masih berupa jalan tanah belum mengalami perkerasan atau pavingisasi. Luasan RTH public belum sesuai (19\%) dan kondisi rumah belum memenuhi semua syarat rumah sehat

2) Ekonomi

Jenis mata pencaharian penduduk pada permukiman kumuh ringan sebagai berikut
Tabel 2

Jenis Mata Pencaharian Penduduk

\begin{tabular}{|c|c|c|}
\hline $\begin{array}{l}\text { Kecamatan } / \mathrm{K} \\
\text { elurahan } \\
\text { (3) }\end{array}$ & $\begin{array}{l}\text { Kelompok } \\
\text { Masyarakat } \\
(4) \\
\end{array}$ & $\begin{array}{l}\text { Kegiatan Ekonomi } \\
\text { (5) }\end{array}$ \\
\hline Tambak Wedi & $\begin{array}{l}\text { Kampung } \\
\text { Nelayan }\end{array}$ & $\begin{array}{ll}\text { - } & \text { Penangkapan Ikan } \\
\text { - } & \text { Penyaluran hasil ikan laut } \\
\text { - } & \text { Pengolahan hasil laut }\end{array}$ \\
\hline $\begin{array}{l}\text { Bulak } \\
\text { Banteng }\end{array}$ & Pergudangan & $\begin{array}{ll}\text { - } & \text { Pergudangan (meubel, barang } \\
\text { bekas, besi bekas) } \\
\text { - } \quad \text { Wirausaha (Bengkel las) } \\
\text { - } \quad \text { Petani tambak } \\
\text { - Pedagang Pasar }\end{array}$ \\
\hline $\begin{array}{l}\text { Tanah Kali } \\
\text { Kedinding }\end{array}$ & pedagang & $\begin{array}{l}\text { - } \quad \text { Pedagang Pasar } \\
\text { - Wirausaha (industry pengolahan } \\
\text { hasil laut) }\end{array}$ \\
\hline
\end{tabular}

Sumber. Survey Primer dan wawancara, 2015

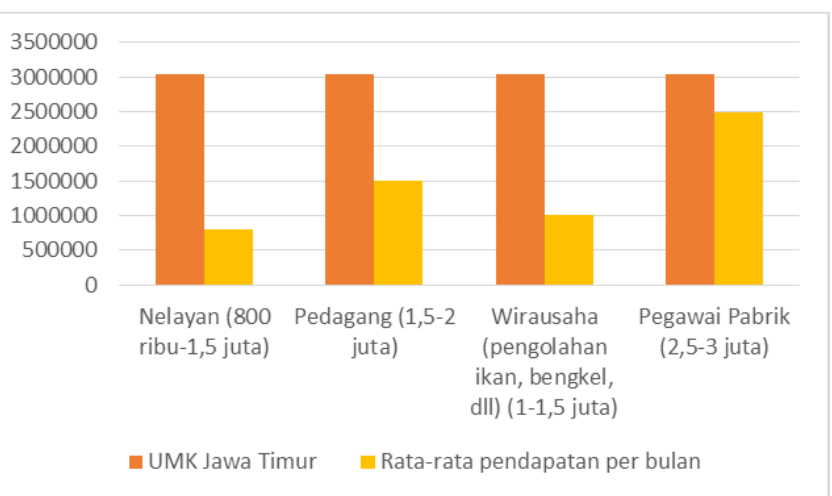

Gambar 3. Tingkat Pendapatan masyarakat dibanding UMK Kota Surabaya

3) Sosial

Tingkat partisipasi masyarakat pada Kecamatan Kenjeran 30-60\% dari jumlah warga, dimana partisipasi masyarakat dibagi dalam partisipasi langsung berupa kerja bakti, bersih sungai, dan perbaikan jalan; dan partisipasi tidak langsung berupa perbaikan drainase, perbaikan jalan, bedah rumah, pelatihan kewirausahaan. Gaya dan budaya hidup masyarakat permukiman kumuh sedang Kenjeran masih bergaya pedesaan, dimana dipengaruhi oleh mata pencaharian warganya.

4) Kelembagaan

Institusi yang langsung berhubungan dengan permasalah lingkungan permukiman kumuh di Kenjeran adalah Bappeko Kota Surabaya, Dinas PU dan Cipta Karya Kota Surabaya, Dinas Kebersihan dan Pertamanan Kota Surabaya, serta Instansi tingkat Kecamatan dan Kelurahan. Sedangkan Kebijakan yang bersangkutan langsung adalah RTRW Kota Surabaya, RDTRK UP Tambak Wedi, SPIPP, dan RP4D.

B. Identifikasi faktor-faktor yang mempengaruhi perkembangan permukiman kumuh di Kecamatan kenjeran dengan pendekatan Eco-Settlements

Identifikasi faktor pada sasaran dua ini menggunakan Analisa Delphi, dimana analisis dilakukan pada 8 responden berpengaruh yang terpilih melalui analisis stakeholder. Analisis dilakukan sebanyak dua tahap hingga menemukan jawaban konsensus dan sesuai. Analisa Delphi ini melewati 1 tahapan 
iterasi sehingga didapat 13 faktor yang mempengaruhi adalah sebagai berikut :

1) Kualitas Lingkungan, kualitas lingkungan disini meliputi sarana dan prasarana dasar permukiman

2) Rumah Sehat, dimana sub faktornya berupa pencahayaan, sirkulasi udara, ketersediaan MCK dan ketersediaan RTH privat

3) Guna Lahan di sekitar wilayah permukiman kumuh

4) Faktor Tingkat Kesempatan Kerja bagi masyarakat

5) Faktor Tingkat Pendapatan masyarakat

6) Faktor Tingkat pemberdayaan masyarakat di wilayah penelitian

7) Faktor Tingkat kepadatan penduduk

8) Faktor urbanisasi yang terjadi di wilayah penelitian

9) Faktor tingkat pendidikan masyarakat

10) Faktor tingkat partisipasi masyarakat

11) Faktor budaya masyarakat

12) Faktor kapasitas institusi terhadap wilayah permukiman kumuh di Kecamatan Kenjeran

13) Faktor aturan yang berlaku pada wilayah permukiman kumuh di Kecamatan Kenjeran.

Dari ke 13 faktor diatas dicross check kembali, dan dirinci mana faktor tersebut yang sesuai dengan masing-masing kelurahan yang ada di Kecamatan Kenjeran

Tabel 3

Faktor berpengaruh per Kelurahan

\begin{tabular}{|c|c|}
\hline $\begin{array}{l}\text { No } \\
(1)\end{array}$ & $\begin{array}{l}\text { Faktor-faktor } \\
\quad(2)\end{array}$ \\
\hline 1 & $\begin{array}{l}\text { Permukiman kumuh ringan pada Kelurahan Tambak Wedi, } \\
\text { Kecamatan Kenjeran adalah: }\end{array}$ \\
\hline & 1. Kualitas Lingkungan \\
\hline & Rumah Sehat \\
\hline & 3. Guna Lahan \\
\hline & Faktor Tingkat Kesempatan Kerja bagi masyarakat \\
\hline & 5. Faktor Tingkat Pendapatan masyarakat \\
\hline & 6. Faktor Tingkat pemberdayaan masyarakat \\
\hline & Faktor Tingkat kepadatan penduduk \\
\hline & Faktor urbanisasi \\
\hline & Faktor tingkat pendidikan masyarakat \\
\hline & 10. Faktor tingkat partisipasi masyarakat \\
\hline & 11. Faktor budaya masyarakat \\
\hline & $\begin{array}{l}\text { 12. Faktor kapasitas institusi terhadap wilayah permukiman } \\
\text { kumuh di Kecamatan Kenjeran }\end{array}$ \\
\hline & $\begin{array}{l}\text { 13. Faktor aturan yang berlaku pada wilayah permukiman } \\
\text { kumuh di Kecamatan Kenjeran }\end{array}$ \\
\hline
\end{tabular}

2 Permukiman kumuh sedang pada Kelurahan Tambak Wedi, Kecamatan Kenjeran adalah :

1. Kualitas Lingkungan

2. Rumah Sehat

3. Guna Lahan

4. Faktor Tingkat Kesempatan Kerja bagi masyarakat

5. Faktor Tingkat Pendapatan masyarakat

6. Faktor Tingkat pemberdayaan masyarakat

7. Faktor Tingkat kepadatan penduduk

8. Faktor urbanisasi

9. Faktor tingkat pendidikan masyarakat

10. Faktor tingkat partisipasi masyarakat

11. Faktor budaya masyarakat

12. Faktor kapasitas institusi terhadap wilayah permukiman kumuh di Kecamatan Kenjeran

13. Faktor aturan yang berlaku pada wilayah permukiman kumuh di Kecamatan Kenjeran

3 Permukiman kumuh sedang pada Kelurahan Bulak Banteng, Kecamatan Kenjeran adalah :

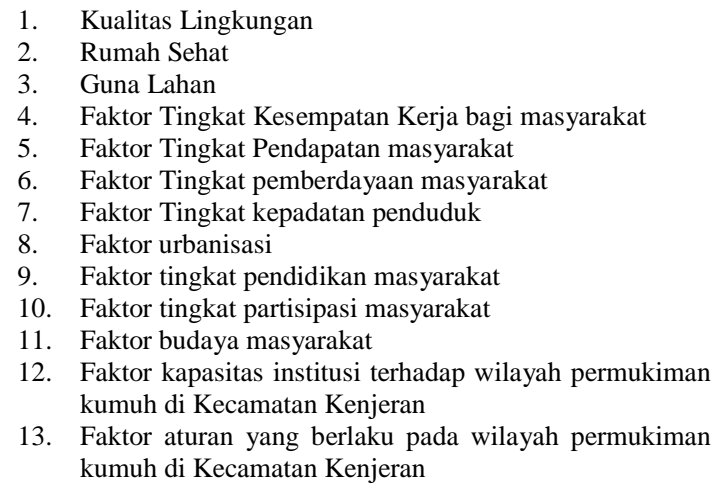

Permukiman kumuh ringan pada Kelurahan Tanah Kali Kedinding, Kecamatan Kenjeran adalah :

1. Kualitas Lingkungan

2. Rumah Sehat

3. Guna Lahan

4. Tingkat kesempatan kerja

5. Tingkat pendapatan masyarakat

6. Faktor Tingkat pemberdayaan masyarakat

7. Faktor Tingkat kepadatan penduduk

8. Faktor urbanisasi

9. Faktor tingkat partisipasi masyarakat

10. Faktor budaya masyarakat

5 Permukiman kumuh sedang pada Kelurahan Tanah Kali Kedinding, Kecamatan Kenjeran adalah :

1. Kualitas Lingkungan

2. Rumah Sehat

3. Guna Lahan

4. Tingkat kesempatan kerja

5. Tingkat pendapatan masyarakat

6. Faktor Tingkat pemberdayaan masyarakat

7. Faktor Tingkat kepadatan penduduk

8. Faktor urbanisasi

9. Faktor tingkat partisipasi masyarakat

10. Faktor budaya masyarakat

6 Permukiman kumuh ringan pada Kelurahan Sidotopo Wetan, Kecamatan Kenjeran adalah :

1. Kualitas Lingkungan

2. Rumah Sehat

3. Guna Lahan

4. Faktor Tingkat pemberdayaan masyarakat

5. Faktor Tingkat kepadatan penduduk

6. Faktor urbanisasi

7. Faktor tingkat partisipasi masyarakat

8. Faktor kapasitas institusi terhadap wilayah permukiman kumuh di Kecamatan Kenjeran

9. Faktor aturan yang berlaku pada wilayah permukiman kumuh di Kecamatan Kenjeran

\section{Arahan Penataan Lingkungan Permukiman Kumuh di Kecamatan Kenjeran dengan pendekatan Eco-Settlements}

Penentuan arahan penataan lingkungan permukiman kumuh dilakukan menggunakan analisis triangulasi . Dimana analisis ini mengkomparasikan fakta empiris, regulasi terkait, serta teori dan base practice. Arahan pengembangan difokuskan kepada 4 pilar utama eco settlements yaitu

1) Ekologi : Penambahan dan peningkatan kualitas prasarana dan sarana permukiman berupa perbaikan drainase, pembangunan sanitasi, pembangunan kolam limbah cair, bedah rumah, serta pavingisasi dan perkerasan jalan, 
relokasi rumah yang melanggar aturan, serta pengadaan sanksi

2) Ekonomi : Menerapkan ekonomi ramah lingkungan dan Memberdayakan ekonomi masyarakat kelas menengah berbasis home industry dengan memberikan pelatihan skill, bantuan operasional.

3) Sosial : Peningkatan ketertiban administrasi warga, pembentukan lembaga masyarakat

4) Kelembagaan : Meningkatkan kualitas institusi dan arahan kebijakan mengenai peningkatan kualitas permukiman kumuh Kecamatan Kenjeran

\section{KESIMPULAN}

Dari hasil pembahasan diatas, dapat ditarik kesimpulan dari penelitian yang dilakukan adalah :

1) Karakteristik Wilayah Permukiman kumuh Kecamatan Kenjeran diidentifikasi melalui analisa deskriptif dimana hasilnya masuk dalam jenis permukiman ringan dan permukiman kumuh sedang

2) Ditemukan faktor yang mempengaruhi perkembangan permukiman kumuh diidentifikasi dengan analisa Delphi kepada 8 stakeholder. Faktor tersebut adalah sebagai berikut aspek Lingkungan (air bersih, drainase, sanitasi, sampah,aksesbilitas, Rumah sehat, dan RTH); Karakteristik ekonomi (jenis pekerjaan, tingkat pendapatan); Sosial (kepadatan penduduk, urbanisasi, budaya masyarakat, pemberdayaan masyarakat); dan Kelembagaan (kapasitas institusi, kerjasama, dan aturan berlaku)

3) Arahan yang dirumuskan dengan alat analisa triangulasi untuk penataan lingkungan permukiman kumuh Kecamatan Kenjeran adalah sebagai berikut :

a. Penambahan dan peningkatan kualitas prasarana dan sarana permukiman pada permukiman kumuh sedang

b. Melakukan renovasi dan rekonstruksi terhadap rumah rumah semi dan non permanen pada permukiman kumuh sedang

c. Menentukan regulasi dan sanksi mengenai bagi penggunaan lahan yang tidak sesuai,

d. Memberdayakan masyarakat ekonomi menengah kebawah dengan program peningkatan ekonomi mandiri ramah lingkungan di prioritaskan pada Kelurahan Tambak Wedi, dan Tanah Kali Kedinding

e. Peningkatan ketertiban administrasi warga untuk menekan angka pendatang, dan juga menjaga keamanan bagi tiap kelurahan di Kecamatan Kenjeran

f. Membentuk kelembagaan masyarakat yang dikhusukan dengan tujuan pengentasan kekumuhan, pengentasan kemiskinan, dan peningkatan kesejahteraan warga, peningkatan kesadaran akan pendidikan,

g. Meningkatkan kualitas institusi dan arahan peningkatan kualitas permukiman kumuh Kecamatan Kenjeran

\section{DAFTAR PUSTAKA}

[1] Undang-Undang No 1 Tahun 2011 tentang Perumahan dan Permukiman

[2] Badan Pusat Statistik Kota Surabaya. 2014. Surabaya dalam Angka 2014. Surabaya : BPS

[3] Laporan Dasar Rencana Pembangunan Perumahan dan Permukiman Daerah (RP4D) 2008-2018. Surabaya : Dinas PU Cipta karya dan Tata Ruang

[4] Aeny, Anisatul. 2014. Evaluasi Kualitas Lingkungan Permukiman Berdasarkan Kriteria Eco-Settlements di Kawasan Permukiman Kumuh Kelurahan Temanggung I, Kecamatan Temanggung Kabupaten Temanggung. Skripsi. Geografi dan Ilmu Lingkungan, Universitas Gajah Mada

[5] Trisnowati, Endang. 2015. Pengaruh Pendekatan Saintifik Terhadap Motivasi dan Prestasi Belajar Mata Pelajaran IPA pada Kelas VII SMPN 1 Wringinanom Gresik. Tesis. Program Studi Teknologi Pendidikan. Pazcasarjana Universitas PGRI Adi Buana Surabaya 